\title{
Performance Optimatization of Yagi Antenna Devices for Detecting Quality Levels River Water Based on Internet of Thing
}

\author{
Irawan Hadi ${ }^{1, *}$ Sholihin Sholihin ${ }^{1,}$ Martinus Mujur Rose ${ }^{1,}$ Adewasti Adewasti ${ }^{1,}$ \\ Ciksadan Ciksadan ${ }^{1}$
}

\author{
${ }^{I}$ State Polytechnic of Sriwijaya \\ "Corresponding author. Email: sholihin@polsri.ac.id
}

\begin{abstract}
The application of performance optimization of the MIMO antenna system device is basically the use of spatial dimensions in increasing diversity in both reception and transmission. Spatial signal processing then becomes the main concept in the Antenna system. Antenna arrangement is an important part in spatial signal processing, to develop smart city. The design of the antenna array will have an influence on the performance of the Antenna system. A number of MIMO research on the antenna aspect is an interesting research that is currently developing.

While the Internet of things is being widely used in today's technological developments. IoT can be interpreted as communication between one device and another using the internet. Advances in IoT technology can facilitate various kinds of work, one of which is to find out water pollution. The components needed in IoT include devices that have an IoT module, devices that connect to the Internet such as Wifi and routers, and a database where everything is collected. The scenario of this system, it is carried out to determine the level of the success of the water turbidity system and the Esp32cam as a microcontroller circuit that uses the Adafruit application and the water turbidity monitor application as internet of things (IoT) technology. Has it worked in accordance with the design of temperature control in surrounding conditions and a dc fan as a smoke exhaust in the room and NodeMcu ESP8266 as a microcontroller the circuit that uses telegram as an Internet of Things (IoT) technology does it work according to the design. The parameters used are the turbine sensor, the esp32cam module, led, the adafruit application and the water turbidity monitoring application for monitoring the state of the water.

The turbine sensor serves as an input to detect the turbidity of the water to be tested which will be processed by nodemcu and the output in the form of a display display serves to provide information in the form of text, if smoke is detected, the Nodemcu Esp32cam will send a notification to the telegram application as a medium of information.
\end{abstract}

Keywords: Adafruit IO, Modul ESP32 cam, Internet of Things, Sensor turbinity, Yagi antenna

\section{INTRODUCTION}

Water is an essential material that plays a very important role in life and for human life. Not only because about $80 \%$ of the human body consists of fluids, but also because in water there are mineral elements needed for human physical development. The higher a person's standard of living, the more human need for water increases. does not contain poison. Physically clean water is indicated by its clear, colorless and odorless state. This condition occurs if the water is not polluted by organic or inorganic materials.

Currently, it is rare for people to understand the quality of the water they consume, most people only recognize clean and dirty water, without knowing the feasibility of the water. Because not all substances contained in water can be seen with the naked eye, so it will be difficult to know whether the water is in accordance with drinking water quality standards or not. Therefore, this paper aims to create a real-time drinking water quality monitoring tool by detecting currently, it is rare for people to understand the quality of the water they consume, most people only recognize clean and dirty water, without knowing the feasibility of water. So, this paper aims to create a real-time drinking water quality monitoring tool by detecting levels of dissolved substances, temperature, turbidity and $\mathrm{pH}$ in IoT-based water. 
While the Internet of things is being widely used in today's technological developments. IoT can be interpreted as communication between one device and another using the internet. Advances in IoT technology can facilitate various kinds of work, one of which is to find out water pollution. The components needed in IoT include devices that have an IoT module, devices that connect to the Internet such as Wifi and routers, and a database where everything is collected. The scenario of this system, it is carried out to determine the level of the success of the water turbidity system and the Esp32cam as a microcontroller circuit that uses the Adafruit application and the water turbidity monitor application as internet of things (IoT) technology. Has it worked in accordance with the design of temperature control in surrounding conditions and a dc fan as a smoke exhaust in the room and Node Mcu ESP8266 as a microcontroller the circuit that uses telegram as an Internet of Things technology does it work according to the design. The parameters used are the turbine sensor, the esp32cam module, led, the adafruit application and the water turbidity monitoring application for monitoring the state of the water.

The turbine sensor serves as an input to detect the turbidity of the water to be tested which will be processed by nodemcu and the output in the form of a display display serves to provide information in the form of text, if smoke is detected, the Nodemcu Esp32cam will send a notification to the telegram application as a medium of information.

\section{DESIGN SYSTEM}

In the design tool for monitoring dust particles in the air with the internet of things communication system using the blynk application. The layout of the components in this circuit can be seen in Fig.1.

Automatically, Fritzing will generate 3 layouts, namely Breadboard, Schematic, and PCB images. Breadboard is a layout (image) that will display an image of the original (physical) component. Schematic is a layout that will display an image in the form of a schematic design of the circuit you created. While the PCB is a layout that will display an image in the form of a design on the PCB.

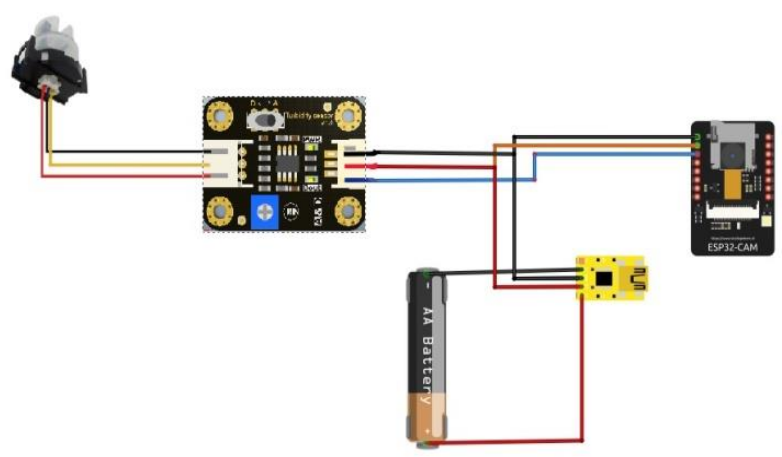

Figure 1 Design Component Layout
Next, Fritzing is an open source software for hardware (electronic) design that is intended to support designers, artists, or hobbyists to be able to work creatively with interactive electronic devices.

Like the quote above, Fritzing is aimed at designers, or those who like to tinker with interactive electronic devices such as arduino and devices from Sparkfun in order to easily document the designs they make. For that purpose, the Fritzing interface was made as interactive and easy as possible so that it can be used by people who have minimal knowledge of symbols of electronic devices. In Fritzing, there are already ready-to-use schematics of various Arduino microcontrollers and their shields (this software is specifically designed for designing and documenting creative products using Arduino microcontrollers). So those of you who like to tinker with Arduino, will get great benefits from this software.

How to use it is very easy, because this software uses the concept of drag $n$ drop. You just select the component you want in the Parts section, drag the component on the main window and drop it. Likewise with the wiring, just drag $\mathrm{n}$ drop.

Automatically, Fritzing will generate 3 layouts, namely Breadboard, Schematic, and PCB images. Breadboard is a layout (image) that will display an image of the original (physical) component. Schematic is a layout that will display an image in the form of a schematic design of the circuit you created. While the PCB is a layout that will display an image in the form of a design on the PCB.

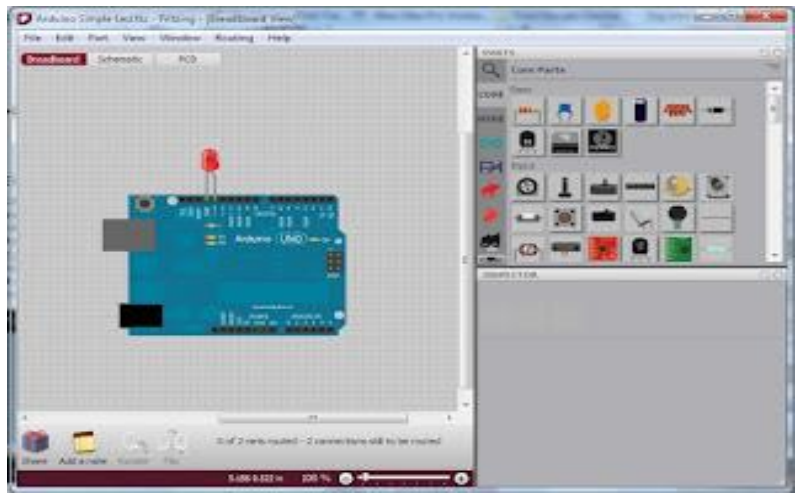

Figure 2 Breadboard Layout

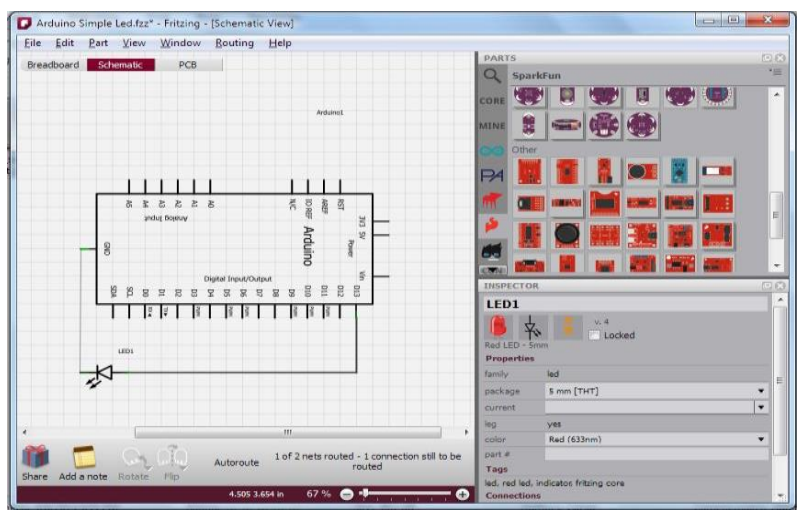

Figure 3 Shcematic Layout 


\section{CURRENT RESULT}

In determining the results of the test, the researcher will use uses the signal processing jobs that will be practiced are Power Supply Measurements and High Pass Filters, Power Supply Measurements and Band Pass Filters, Power Supply Measurements and Low Pass Filters, Power Supply Measurements and OP-AMP.

Table 1. Water turbinity detection system testing

\begin{tabular}{|c|c|c|c|c|}
\hline \multirow{4}{*}{ Device } & $\begin{array}{c}\text { Testing } \\
\text { number }\end{array}$ & $\begin{array}{c}\text { Sensor value } \\
\text { on serial } \\
\text { monitor }\end{array}$ & Condition & $\begin{array}{c}\text { Test } \\
\text { material }\end{array}$ \\
\hline \multirow{4}{*}{ Turbinity } & 1 & 0 & Cloudy & $\begin{array}{c}\text { River } \\
\text { water }\end{array}$ \\
\cline { 2 - 5 } Sensor & 2 & 0 & Cloudy & $\begin{array}{c}\text { River } \\
\text { water }\end{array}$ \\
\cline { 2 - 5 } & 3 & 0 & Cloudy & $\begin{array}{c}\text { River } \\
\text { water }\end{array}$ \\
\cline { 2 - 5 } & 5 & 1 & Not Cloudy & $\begin{array}{c}\text { River } \\
\text { water }\end{array}$ \\
\cline { 2 - 5 } & 6 & 1 & Not Cloudy & $\begin{array}{c}\text { River } \\
\text { water }\end{array}$ \\
\cline { 2 - 5 } & 7 & 1 & Not Cloudy & $\begin{array}{c}\text { River } \\
\text { water }\end{array}$ \\
\cline { 2 - 5 } & 7 & 1 & $\begin{array}{c}\text { River } \\
\text { water }\end{array}$ \\
\hline
\end{tabular}

Table 2. Measuremnet results by telegram

\begin{tabular}{|c|c|c|c|}
\hline $\begin{array}{c}\text { Testing } \\
\text { number }\end{array}$ & $\begin{array}{c}\text { Sensor value on } \\
\text { adafuit (\%) }\end{array}$ & $\begin{array}{c}\text { Sensor value on } \\
\text { the water } \\
\text { turbnity monitor } \\
\text { application }\end{array}$ & $\begin{array}{c}\text { Delivery time } \\
\text { (s) }\end{array}$ \\
\hline 1 & 0 & Cloudy & 3 \\
\hline 2 & 0 & Cloudy & 3 \\
\hline 3 & 1 & Cloudy & 3 \\
\hline 4 & 1 & Not Cloudy & 2 \\
\hline 5 & 3 seconds delivery time on the application \\
\hline Avarages & \multicolumn{3}{|c|}{}
\end{tabular}

\section{CONCLUSION}

Turbinity sensor serves to detect turbidity in the water. The output from the sensor will provide data directly to the water turbidity monitor application and adafruit in the form of text, this water turbidity detector must be connected to wifi so that the internet network can monitor and can be done anywhere. The delivery time takes about 3 seconds to send to the application Each level value on the sensor detected is different, depending on the water being tested.

\section{AUTHORS' CONTRIBUTIONS}

Contribution to the authors is making research data collection, with the testing how many the delivery time takes about 3 seconds to send to the application. Each level value on the sensor detected is different, depending on the water being tested.

\section{ACKNOWLEDGMENTS}

In writing this paper, the researcher has conducted several sample trials with reference to references as reference material, to improve this paper.

The researcher also thanks the previous authors, and the researcher also apologizes if there are different writing words.

Thank you once again we the researchers say.

\section{REFERENCES}

[1]. A.A. Asaker, R.S. Ghoname and A.A. Zekry, "Design of a planar MIMO antenna for LTEadvanced", International Journal of Computer Applications (0975 - 8887), vol. 115, no. 12, pp. 27-33, April 2015.

[2]. Eka susanti, Rosita febriani, Sholihin, Emilia hesti, 2018, "The design of hand gesture robot software based on wireless technology", IEEE conferences ICOIACT 2018, Indonesia, p.p 401 - 406.

[3]. X. Liu and M. E. Bialkowski, "Effect of antenna mutual coupling on MIMO channel estimation and capacity", International Journal of Antennas and Propagation, vol. 2010, 2010.

[4]. A. Emadeddin, S. Shad, Z. Rahimian and H.R. Hassani, "High mutual coupling reduction between microstrip patch antennas using novel structure", $A E U$ - International Journal of Electronics and Communications, vol. 71, pp. 152156, 2017.

[5]. Sholihin, Eka Susanti, "Humanoid Robot Control System Balance Dance Indonesia and Reader Filters Using Complementary Angle Value", E3S Web of Conferences 31, 2018.

[6]. Hussein Hamed Mahmoud Ghouz, "Novel Compact and Dual-Broadband Microstrip MIMO Antennas for Wireless Applications", Progress In Electromagnetics Research B, vol. 63, pp. 107 $121,2015$.

[7]. I.K. Sokhi, R Ramesh and K Usha Kiran, "Design of UWB-MIMO antenna for wireless applications", 2016 International Conference on Wireless Communications Signal Processing and Networking (WiSPNET), pp. 962-966, 2016

[8]. G. Han, L. Han, R. Ma, Q. Zeng and W. Zhang, "A novel MIMO antenna with DGS for high isolation", $2016 \quad$ IEEE MTT-S International Conference on Numerical Electromagnetic and Multiphysics Modeling and Optimization (NEMO), pp. 1-2, 2016.

[9]. Sholihin, Eka Susanti, A. A. Pramudita and M. M. Rose, "MIMO antenna with cross polarisation printed yagi elements for MIMO router", Proc. 2017 3rd International Conference on Wireless and Telematics (ICWT) Palembang Indonesia, pp. 65-69, July 2017 